\title{
Regulations on Wearing Gold Ornaments
}

Prof. Dr. Krishna B. Thapa*

It is commonly known that Nepal has divergent ethnicity. Therefore, Cultural diversity is a notable feature of Nepalese society. Although it has various positive aspects, several weaknesses are associated with the cultural variation. In fact, maintenance of social harmony and unity among the nationalities is not so easy. Cultural identity either of individuals or groups always remain as a very sensitive matter. One report suggests that occurrence of intra group conflict has been a common features of developing countries. ${ }^{1}$

One of the characteristics of divergent cultures is that they originate, develop and change spontaneously, but there could be a number of reasons to continue the process. The word culture connotes deeper meaning however, it can be manifested differently. People from different cultures behave differently. They follow various ways of living. At the practical level, people use various cultural components. Costume remains vital in day to day life. Within the periphery of costume, the practice of wearing ornaments is another important part of cultural behaviour. The costume typology defines various stages of human civilization.

Wearing various ornaments is a part of cultural behaviour. Although it is associated with decoration luxurious item, it is very important aspect of culture. Since the ancient times, people used both metallic or non-metallic ornaments. During the course of time, it became associated with power, prestige and dignity. It is true at least in the case of Nepalese society. The powerful section in the society imposed restrictions on free use of ornaments. In fact, restrictions were imposed on the lower strata so far.

The social history of Nepal reveals the fact that at least since the later medieval period, the rulers started imposing putting several restrictions on the use of valuable ornaments.

King Jayasthiti Malla (1380-94 A.D.), an early medieval ruler reorganized the Nepalese society based on caste system. He had not only divided the society into several caste hierarchies but also promulgated rules restricting a section of the society to wear specific costumes and ornaments. In fact, the Podes (sweepers)

Dr. Krishna B. Thapa is a Professor in the Central Department of History, Tribhuvan University, Kirtipur, Kathmandu, Nepal.

1. M. M. Chaudri, "The Limits and Challenges of Educational Technology in the Paradigm of Sustainable Development in India," Journal of Higher Education, Vol.21,No.1, 1998, New Delhi, p.30. 
were prohibited to wear ornaments made of gold. ${ }^{2}$ Similarly, Kasai (butchers) were prohibited from wearing full sleeve Nepali vest known as Daura. Those castes along with the Kulu were prohibited to live in tile roofed houses ${ }^{3}$. During that time, the lower caste people were prohibited to wear gold ornaments. It obviously indicates lower status in the society. The rules enancted so far can, by no means be interpreted as a system that can maintain social 'equality and harmony'. One should be aware of the fact that King Jayasthiti Malla reorganized the society on the basis of Hindu classical texts. The division of the society on such basis certainly leads to make distinction in using ornaments also. The analysis of the reforms shows that Jayasthiti Malla did not impose any kind of restriction on the upper caste people in matters of wearing gold ornaments. Later, King Ram Shah (1606-33 A.D.) of Gorkha imposed restrictions against the upper class to use gold ornaments in feet. The exception was that the royalty had right to wear gold ornaments in any part of the body . It is supported by the document discussed in this paper. ${ }^{4}$

According to the document, an order on wearing gold ornaments was already issued by King Ram Shah of Gorkha, but later, the rule was not properly followed due to different reasons. ${ }^{5}$ The rule as such represents the norms and values of a feudal society where there was difference between social groups even in wearing different types of ornaments. However, one should be aware of the fact that the system remained a part of that society, which tended to continue even in the $19^{\text {th }}$ century after it was revived. The order reviving the 200 years old system was issued in 1896 V.S.(June 1839 A.D.) during the time of King Rajendra Bikram Shah, which remained in effect throughout the Rana regime.

This order has four provisions dealing with wearing ornaments. The new system was a continuity to the system introduced by the King of Gorkha. The rule, in fact is a proof to define contemporary society as well as differences between social hierarchies.

According to the provisions of the document, the queen was permitted to wear gold ornaments in feet. The wives of Chautariyas could also use gold ornaments in foot only but they require permission from the king. The Brahmins, Rajput, Khas and Magars etc. were permitted to wear gold ornaments only in hands, if the King permitted to do so. Finally, the document mentions that sons and

2. Balchandra Sharma, Nepalko Aitihasik Ruprekha, Varanasi: Krishna Kumari Devi, 2022 B.S., p.139. Also see: Chandra Bikram Budhathoki (ed.), Jayasthiti Malla Ko Sudhar, Lalitpur: Sajha Prakashan, 2039 B.S., pp.12-13.

3. Ibid.

4. Regulation On Wearing Gold Ornaments - 1896 B.S., Poka no. 10, Bahi no. 70, S.N. 186, Record Section of the Department of Revenue, Kathmandu.

5. Ibid. 
daughters of the Chautariyas were supposed to wear gold ornaments in foot only during their childhood.

This document seems to be valuable in order to anlayse social history of the period. It defines power, prestige and dignity of different hierarchical groups in the Nepalese society. Due to its historical importance, full text of the order is as follows: ${ }^{6}$

cfu] c3L >L \% IhHo" afHofHo" dxf/fh /fd zfx=af6 ;'jg\{sf uxgf nfpGof s'/fsf] lylt j+b]h jfwL jS;g' eofsf] /x]5= jLrdf s]lx if8 j8 kg\{ hfbf ;f] lylt ;RofO\{ cj pk|fGt= ;'jg\{sf uxgf nfpGof lyltsf] j+b]h jfwL aS:of\}+-

k|yd j+b]h - xfd|f kf6 j+bL /fgLn] uf]8fdf ;'jg\{sf uxgf nfpg'

bf]>f] j+b]h - e\}ofb rf\}t/Lofx?sf rf\}tflg\{x?n] xfdLjf6 jS:of dfq uf]8fdf ;'jg\{sf uxgf nfpg'

t]>f] j+b]h- j|fXdOf /hk't if; du/ k|e[tL c? hftn] eGof xftdf klg xfdLn] jS:of dfq ;'jg\{sf uxgf nfpg'

rf\}yf] j+b]h - efO rf\}t/Lofsf /f\}t]nf /f\}t]nLx?n] jfnif sfndf dfq\} ;'jg\{sf uxgf uf]8fdf nfpg' IdtL ;b/ -!*(^ h]i7 jbL !\# /f]h @ z'ed!_ 